\title{
BCG stimulation promotes dendritic cell proliferation and expression of VDR and CYP27B1 in vitamin D-deficient mice
}

\author{
HUIFENG YANG* ${ }^{*}$ HAOCONG ZHANG* ${ }^{*}$ YU LI, LIANGBI XIANG and JUN LIU \\ Department of Orthopedics, General Hospital of Northern Theater Command, Shenyang, Liaoning 110015, P.R. China
}

Received September 21, 2018; Accepted June 12, 2019

DOI: $10.3892 / \mathrm{mmr} .2019 .10780$

\begin{abstract}
Vitamin D deficiency may lead to an increased risk of tuberculosis. In the present study, the effects of Mycobacterium tuberculosis (Mtb) infection on dendritic cells (DCs) derived from vitamin D-deficient mice or normal control mice were investigated. A vitamin D-deficient mouse model was established, and bone marrow-derived DCs (BMDCs) were isolated and treated with GM-CSF and interleukin (IL)-4 for 6 days, followed by an additional $24 \mathrm{~h}$ of treatment with Bacillus Calmette-Guérin (BCG). The expression levels of surface molecules of DCs, including integrin alpha-X and T-lymphocyte activation antigen CD86, were significantly increased by BCG in the vitamin D-deficient mice model group compared with the control group, while those of T-lymphocyte activation antigen CD80, major histocompatibility complex class I and major histocompatibility complex class II were significantly decreased. These changes were BCG concentration-dependent. In addition, the levels of IL-4, IL-6 and IL-10 in the BMDCs from the vitamin D-deficient mice were significantly decreased compared with the control mice, while the levels of tumor necrosis factor- $\alpha$, IL-5, IL-2, IL-12 and interferon- $\gamma$ were significantly increased. Furthermore, the expression levels of vitamin D receptor (VDR) and CYP27B1 protein in the BMDCs from the vitamin D-deficient mice were decreased compared with the control. BCG significantly increased the expression levels of VDR and CYP27B1 in the BMDCs. The DCs treated with BCG significantly induced the viability of $\mathrm{CD}^{+} \mathrm{T}$ lymphocytes. Therefore, $\mathrm{BCG}$ increases DCs and may enhance immunofunction, which may assist in preventing the risk of tuberculosis in patients with a vitamin D deficiency.
\end{abstract}

Correspondence to: Dr Jun Liu, Department of Orthopedics, General Hospital of Northern Theater Command, 83 Wenhua Road, Shenhe, Shenyang, Liaoning 110015, P.R. China

E-mail: 1301031@163.com

*Contributed equally

Key words: vitamin D deficiency, Bacillus Calmette-Guerin, dendritic cells, vitamin $\mathrm{D}$ receptor

\section{Introduction}

Tuberculosis is a chronic infectious disease caused by various strains of Mycobacterium tuberculosis (Mtb) that causes $\sim 200$ million mortalities annually worldwide (1). Vitamin D deficiency is closely associated with tuberculosis $(2,3)$. Mtb affects cell morphology, immunogenicity and drug resistance. Mutations lead to the emergence of multi-drug resistance (4).

Prior to the identification of specific anti-tuberculosis drugs, vitamin D was used for the clinical treatment of tuberculosis. Following the development of anti-tuberculosis drugs in the mid-1950s, the use of vitamin D treatment for tuberculosis decreased (5). The most important members of the vitamin D family are vitamin D2 and vitamin D3. Vitamin D3 is metabolized to 25 hydroxyvitamin D3 [25(OH)D3] in hepatocytes. Subsequently, 25(OH)D3 is bound with $\alpha$-globulin and transferred to the kidney, where it is hydroxylated by 25 -hydroxyvitamin D-1 $\alpha$ hydroxylase, mitochondrial (CYP27B1) and converted into the biologically active $1,25(\mathrm{OH}) 2 \mathrm{D} 3$, which exerts biological functions $(6,7)$.

The biological effects of $1,25(\mathrm{OH}) 2 \mathrm{D} 3$ depend on intracellular specific vitamin D receptor (VDR)-mediated signaling $(8,9)$. Vitamin $\mathrm{D}$ regulates the innate immune response and the release of cytokines and chemokines against pathogenic microorganisms (10). Vitamin D has been demonstrated to have significant anti-inflammatory effects against a variety of bacterial infections (11). As early as the 1980s, Rook et al (12) demonstrated that vitamin D enhanced the bactericidal activity of macrophages in vivo, in order to combat treatment resistance of Mtb. Vitamin D serves an important role in anti-tuberculosis immunity (13).

With the progression of studies examining the role of $25(\mathrm{OH}) \mathrm{D} 3$ in immunity, the mechanism of vitamin $\mathrm{D}$ in the prevention and treatment of tuberculosis has been gradually elucidated.Liu et al (2) confirmed that vitamin D deficiency may inhibit natural immune function, resulting in susceptibility to tuberculosis infection, and suggested that vitamin D enhanced the ability of macrophages to kill bacteria by increasing the antimicrobial peptide secreted by macrophages. Following the activation of the macrophagic toll-like receptor $2 / 1$ signaling pathway by the Mtb 19-kDa lipoprotein, the expression levels of VDR and CYP27B1 are upregulated (2). The majority of the biological effects of $1,25(\mathrm{OH}) 2 \mathrm{D} 3$ are mediated by its interaction with VDR. VDRs are present in numerous types of cells, and serve important roles as an agonist-activated 
transcription factor in the immune system (8). VDR is expressed in T lymphocytes, B lymphocytes and monocytes that differentiate into dendritic cells (DCs) (14). Mature DCs express sterol 26-hydroxylase, mitochondrial (CYP27A1) and CYP27B1 (14). Cultures of DCs are able to convert vitamin D3 to $1,25(\mathrm{OH}) 2 \mathrm{D} 3(14)$.

In the present study, the effects of Mtb infection on DCs derived from vitamin D-deficient mice or normal mice were investigated.

\section{Materials and methods}

Construction of vitamin D-deficient mouse model. A total of 30 male SPF C57BL/6 mice, aged 6-8 weeks old and weighing 20-25 g, were purchased from Changzhou Cavens Laboratory Animal, Co., Ltd. The animals were treated in accordance with animal ethics standards (15) during the experiment and the study was approved by the Committee for Experiments with the Use of Laboratory Animals in Shenyang Military Region General Hospital (Shenyang, China; approval no. AE20160823).

The mice were randomly divided into the following two groups, which were housed separately: Vitamin D-deficient mice model group; and normal control group. The vitamin D-deficient mice model group was given vitamin D-deficient feed, and the normal control group was provided with normal feed. The mice in the two groups were placed on an ultra-clean bench and protected from light. The mice were then exposed to air for $12 \mathrm{~h}$ and irradiated with a yellow fluorescent lamp (18W/41/4P, Philips Healthcare) containing no UV light for $12 \mathrm{~h}$. Following exposure, the mice were kept in the dark for an additional $12 \mathrm{~h}$. After 12 weeks, the mice were sacrificed by exsanguination under $2 \%$ isoflurane anesthesia (16) in order to minimize animal suffering, and were continuously monitored for respiration and temperature. Complete anesthetization was defined as a loss of consciousness, loss of awareness of sensation and suppression of the autonomous reflex activity. Death was confirmed by either cervical dislocation or cessation of circulation.

Animals were checked twice daily. Moribund animals were sacrificed during the experiments using humane endpoints, using following criteria (17): i) Major organ failure or medical conditions unresponsive to treatment such as severe respiratory distress, icterus, uremia, intractable diarrhea or self-mutilation; ii) clinical or behavioral signs unresponsive to appropriate intervention persisting for $24 \mathrm{~h}$ including significant inactivity, labored breathing, sunken eyes, hunched posture, piloerection/matted fur, one or more unresolving skin ulcers and abnormal vocalization when handled. The NC3Rs Animal Research: Reporting of in vivo experiments guidelines (18) were followed. After 12 weeks, there were 10 mice in the vitamin D-deficient mice model group and 12 mice in the normal control group. The tail of each mouse was clamped under isoflurane anesthesia and $100 \mu$ l blood was collected. The levels of 25(OH)D3 (cat. no. LS-F5643-1; LifeSpan BioSciences) and 1,25(OH)2D3 (cat. no. MBS263019; MyBioSource, Inc.) in the serums were determined by ELISA.

Bone marrow-derived $D C$ (BMDC) preparation and induction of DCs in vitro. The C57BL/6 mice were sacrificed by cervical dislocation and then were immersed in $75 \%$ alcohol for $5 \mathrm{~min}$. The tibia and femur were removed under aseptic conditions and immersed in RPMI-1640 medium (Gibco; Thermo Fisher Scientific, Inc.) containing 1\% fetal bovine serum (Hyclone; GE Healthcare Life Sciences). The ends of the bones were removed with scissors and a $1 \mathrm{ml}$ syringe was used to repeatedly rinse the marrow cavity with RPMI-1640 medium. The bone marrow was washed into a sterile culture dish. The cell suspension in the culture dish was collected, and the supernatant and red blood cells were discarded using centrifugation at $300 \mathrm{x}$ for $5 \mathrm{~min}$ at $4^{\circ} \mathrm{C}$. The cells were resuspended with RPMI-1640 medium $+10 \%$ FBS and inoculated in $24-w e l l$ culture plates $\left(1 \times 10^{6}\right.$ cells $/ \mathrm{ml}$ per well $)$ with the cytokines granulocyte-macrophage colony-stimulating factor (20 ng/ml; cat. no. G5035; Sigma-Aldrich; Merck KGaA) and interleukin (IL)-4 (10 ng/ml; SRP3211; Sigma-Aldrich; Merck KGaA) for 6 days in a cell culture incubator at $37^{\circ} \mathrm{C}$ and $5 \% \mathrm{CO}_{2}$. The cells were cultured for an additional $24 \mathrm{~h}$ in the presence of 0,1 and $2 \mathrm{mg} / \mathrm{ml}$ Bacillus Calmette-Guérin antigen (BCG; Sinopharm Chemical Reagent Co., Ltd.), and then harvested as DCs. Cell morphology during BMDC induction from days 1 to 6 was observed by inverted light microscopy (magnification, x40; Leica Microsystems GbmH).

Identification of DC phenotype. The DCs were digested with $0.25 \%$ trypsin for $3 \mathrm{~min}$, centrifuged at $300 \mathrm{xg}$ for $5 \mathrm{~min}$ at $4^{\circ} \mathrm{C}$ and then the supernatant was discarded. The cells were resuspended in $1 \mathrm{ml}$ of $1 \%$ BSA/PBS buffer. The cell concentration was adjusted to $1 \times 10^{6}$ cells $/ \mathrm{ml}$ and the cells were fixed with $0.1 \mathrm{ml}$ polyformaldehyde for $30 \mathrm{~min}$ at $25^{\circ} \mathrm{C}$ Subsequently, fluorescein isothiocyanate-labeled integrin alpha-X (CD11c; 1:50; 130-110-700; Miltenyi Biotech), T-lymphocyte activation antigen CD86 (CD86; 1:50; 130-102-506; Miltenyi Biotech), T-lymphocyte activation antigen CD80 (CD80; 1:50; 130-116-459; Miltenyi Biotech), major histocompatibility complex class I (MHC-I; 1:50; ab95572; Abcam) and MHC-II (1:50; 130-112-386; Miltenyi Biotech) were added, respectively. Following incubation for $1 \mathrm{~h}$ at $4^{\circ} \mathrm{C}$ in the dark, the cells were washed with $1 \%$ BSA/PBS buffer and measured by a MACSQuant analyzer 10 (Miltenyi Biotech).

Detection of cytokines in the cell supernatant by ELISA. There are 2 types of helper T (Th) lymphocytes: Th1 and Th2 cells. On day 7, the supernatants of the BMDC cultures were collected and an ELISA was used to detect Th1 cytokines, including IL-2 (cat. no. E-EL-M0042c; Elabscience), IL-12 (cat. no. E-EL-M0726c; Elabscience), interferon- $\gamma$ (IFN- $\gamma$; cat. no. E-EL-M0048c; Elabscience) and tumor necrosis factor- $\alpha$ (TNF- $\alpha$; cat. no. E-EL-M0049c; Elabscience), and Th2 cytokines, including IL-4 (cat. no. E-EL-M0043c; Elabscience) and IL-5 (cat. no. E-EL-M0722c; Elabscience), according to the manufacturer's protocol. The expression levels of IL-6 (cat. no. E-EL-M0044c; Elabscience) and IL-10 (cat. no. E-EL-M0046c; Elabscience) were also detected in the DCs.

Western blot analysis. Western blot analysis was used to detect the expression levels of VDR and CYP27B1 in the induced DCs following treatment with BCG. Proteins were extracted 

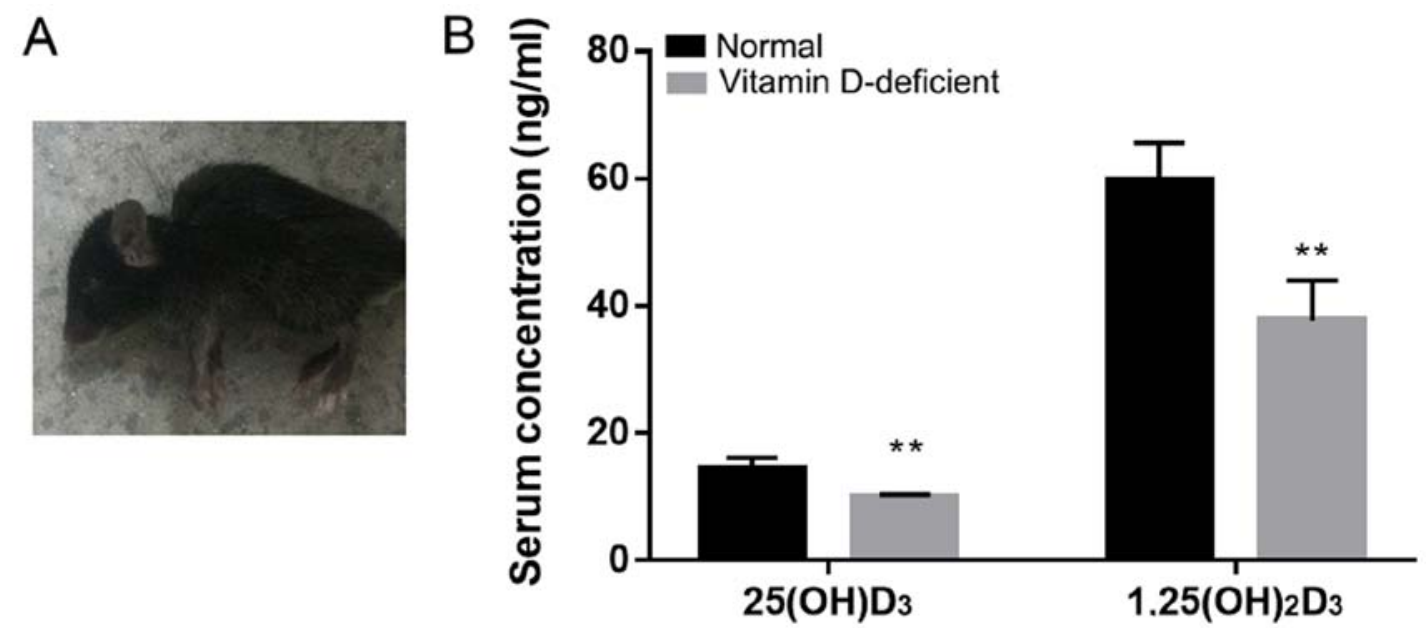

Figure 1. Establishment of a vitamin D-deficient mouse model. (A) A representative vitamin D-deficient mouse. (B) The serum levels of 25(OH)D3 and $1,25(\mathrm{OH}) 2 \mathrm{D} 3$ in the normal and vitamin $\mathrm{D}$-deficient mice. ${ }^{* *} \mathrm{P}<0.01$ vs. respective normal..

with RIPA buffer (Beyotime Institute of Biotechnology) and quantified using a BCA Protein Assay Kit (Beyotime Institute of Biotechnology). In total, 25-50 $\mu \mathrm{g}$ protein per lane was separated on an 10\% SDS-PAGE gel and transferred to a polyvinylidene difluoride (PVDF) membrane (19). The PVDF membrane was cut and incubated with $5 \%$ skimmed milk blocking buffer for $1 \mathrm{~h}$, and then with corresponding primary antibodies against VDR (1:250; sc-1008; Santa Cruz Biotechnology, Inc.) and CYP27B1 (1:400; ab206655; Abcam) at $4^{\circ} \mathrm{C}$ overnight. $\beta$-actin (1:500; cat. no BM0627; Wuhan Boster Biological Technology, Ltd.) was used as loading control. Following 3 washes with PBS plus $0.1 \%$ Tween-20, the membrane was incubated with a horseradish peroxidase-conjugated anti-rabbit secondary antibody (1:5,000; ab7097; Abcam) for $45 \mathrm{~min}$ at $25^{\circ} \mathrm{C}$. Protein expression was detected using a Bio-Rad ChemiDoc ${ }^{\mathrm{TM}} \mathrm{MP}$ imaging system (Bio-Rad Laboratories, Inc.) and performed the densitometric analysis using ImageJ v1.4 (National Institute of Health) (20).

T lymphocyte separation. Blood vessels were collected from the abdominal aorta and placed in lithium heparin anticoagulation vacuum tubes for isolation and culture of peripheral blood mononuclear cells. Lithium heparin anticoagulant (Wuhan DeSheng Biochemical Technology Co., Ltd.) and RPMI-1640 were thoroughly mixed (1:1), and then $2 \mathrm{ml}$ Ficoll lymphocyte separation solution (Sigma-Aldrich; Merck KGaA) was added to the mixture. Following centrifugation for $15 \mathrm{~min}$ at $500 \mathrm{x} \mathrm{g}$ at $4^{\circ} \mathrm{C}$, the mononuclear cell layer was aspirated and the cell suspension concentration was adjusted to $10^{6}$ cells/ml with RPMI-1640. Subsequently, the $\mathrm{CD} 4^{+} \mathrm{T}$ cells were isolated.

MTT detection. Following the stimulation of the DCs with different concentrations of BCG, the cells were collected and adjusted to a cell density of $1 \times 10^{5}$ cells $/ \mathrm{ml}$ at $37^{\circ} \mathrm{C}$ in a $5 \%$ $\mathrm{CO}_{2}$ cell incubator for $30 \mathrm{~min}$. Lymphocytes at a cell density of $1 \times 10^{6}$ cells $/ \mathrm{ml}$ were mixed with equal amounts of DCs. Following incubation of the cells at $37^{\circ} \mathrm{C}$ for 3 days, $10 \mu \mathrm{l}$ MTT (Beyotime Institute of Biotechnology) was added into each well and then the cells were incubated at $37^{\circ} \mathrm{C}$ for $3-4 \mathrm{~h}$ in the dark. Subsequently, $200 \mu \mathrm{l}$ dimethyl sulfoxide was added for $10 \mathrm{~min}$. The optical density value was measured at a wavelength of $492 \mathrm{~nm}$ in order to analyze cell viability.

Statistical analysis. SPSS version 13.0 (SPSS, Inc.) was used for statistical analysis. The data are presented as the mean \pm standard deviation. The inter-group differences were analyzed using one-way analysis of variance followed by the Least Significant Difference test. $\mathrm{P}<0.05$ was considered to indicate a statistically significant difference.

\section{Results}

Establishment of a vitamin D-deficient mouse model. The vitamin D-deficient mice exhibited a significant decrease in walking activity from the 10th week of birth compared with the normal mice. The vitamin D-deficient mice presented with slow movement, darkening of the coat color and back arching (Fig. 1A). The serum levels of 25(OH)D3 and 1,25(OH)2D3 were significantly different between the vitamin $\mathrm{D}$-deficient mice and the normal mice (Fig. 1B). The serum 25(OH)D3 concentration in the normal mice was $14.43 \pm 1.74 \mathrm{ng} / \mathrm{ml}$, and it was $9.99 \pm 0.35 \mathrm{ng} / \mathrm{ml}$ in the vitamin D-deficient mice. The concentration of serum $1,25(\mathrm{OH}) 2 \mathrm{D} 3$ in the normal mice was $59.73 \pm 5.91$ and $37.72 \pm 6.28 \mathrm{ng} / \mathrm{ml}$ in the vitamin D-deficient mice. The results suggest that the vitamin D-deficient mouse model was established successfully.

\section{Morphological observation and identification of BMDCs}

Optical microscope observation of BMDCs. On day 1 of the DC culture, a large number of bone marrow cells were floating in the medium, and a number of cells had adhered to the bottom of the culture plate, which were identified as mononuclear macrophages (Fig. 2A). On the second day, the number of adherent macrophages had increased, and on the third day, the adherent cell mass was increased further. On the fourth day, cells with a small number of short 'needles' were observed floating in the medium and a number of the cell clusters were semi-adherent, which were classified as DC 
A

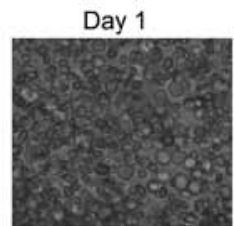

Day 4

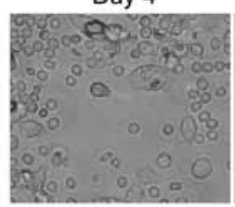

C:

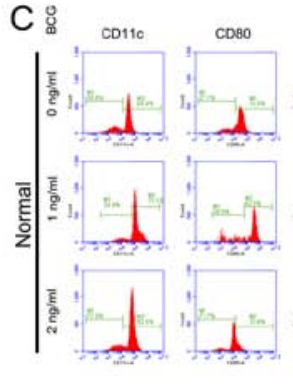

Day 2

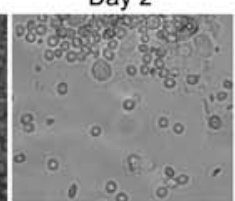

Day 5
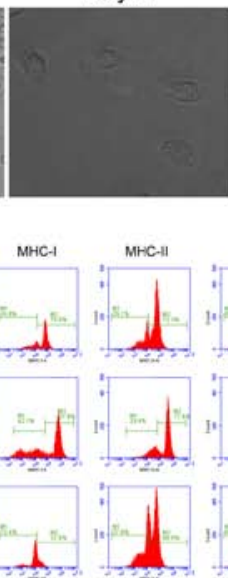

Day 3

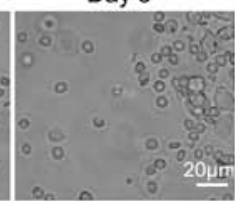

Day 6
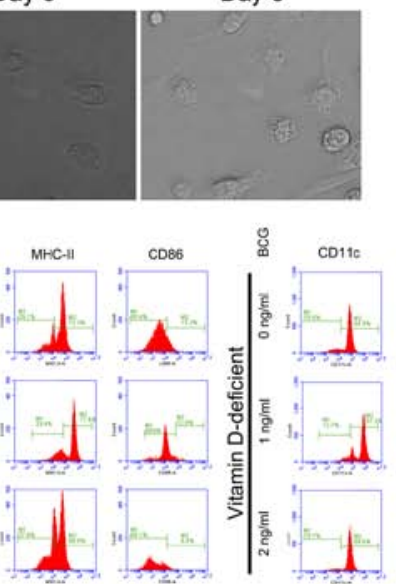
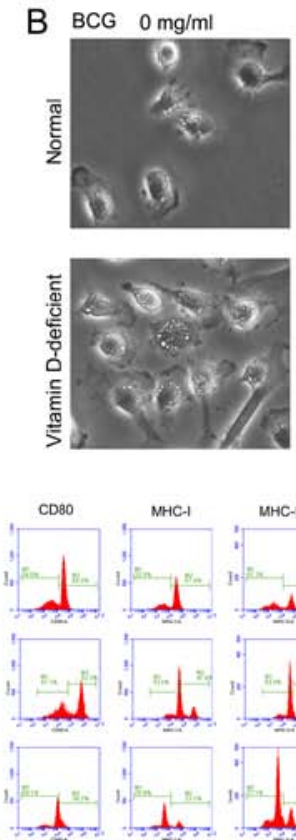
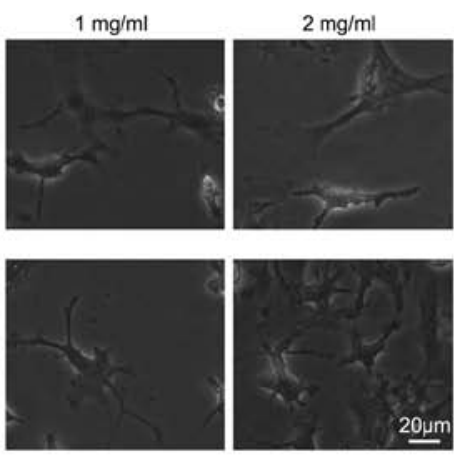

D $=$ Normal $0 \mathrm{mgmil}=$ Vhamin D-deficient $0 \mathrm{mg} / \mathrm{m}$ Normal 2 mgml 1 Vormal 1 Vtamin D-deficient $1 \mathrm{mg} / \mathrm{ml}$

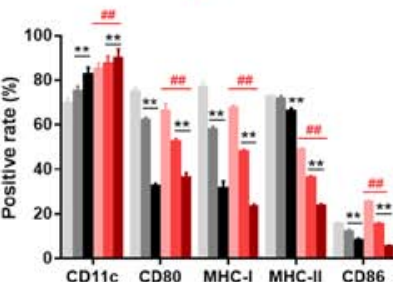

Figure 2. Effect of BCG on BMDC differentiation and maturation. (A) Cell morphology during BMDC induction from days 1 to 6, as observed by light microscopy. (B) BCG stimulated BMDC maturation. (C) Phenotypic changes of the BMDCs induced by BCG stimulation and (D) the levels of the surface molecules of DCs. All images were captured under identical magnification and microscopy conditions. ${ }^{* *} \mathrm{P}<0.01 \mathrm{vs} .0 \mathrm{mg} / \mathrm{ml}$ in the normal control or vitamin $\mathrm{D}$-deficiency groups. ${ }^{\# \#} \mathrm{P}<0.01$, vitamin D-deficiency group vs. normal control group. Scale bar, $20 \mu \mathrm{m}$. BCG, Bacillus Calmette-Guérin; BMDC, bone marrow-derived dendritic cell; CD11c, integrin alpha-X; CD80, T-lymphocyte activation antigen CD80; MHC-I, major histocompatibility complex class I; MHC-II, major histocompatibility complex class II; CD86, T-lymphocyte activation antigen CD86.

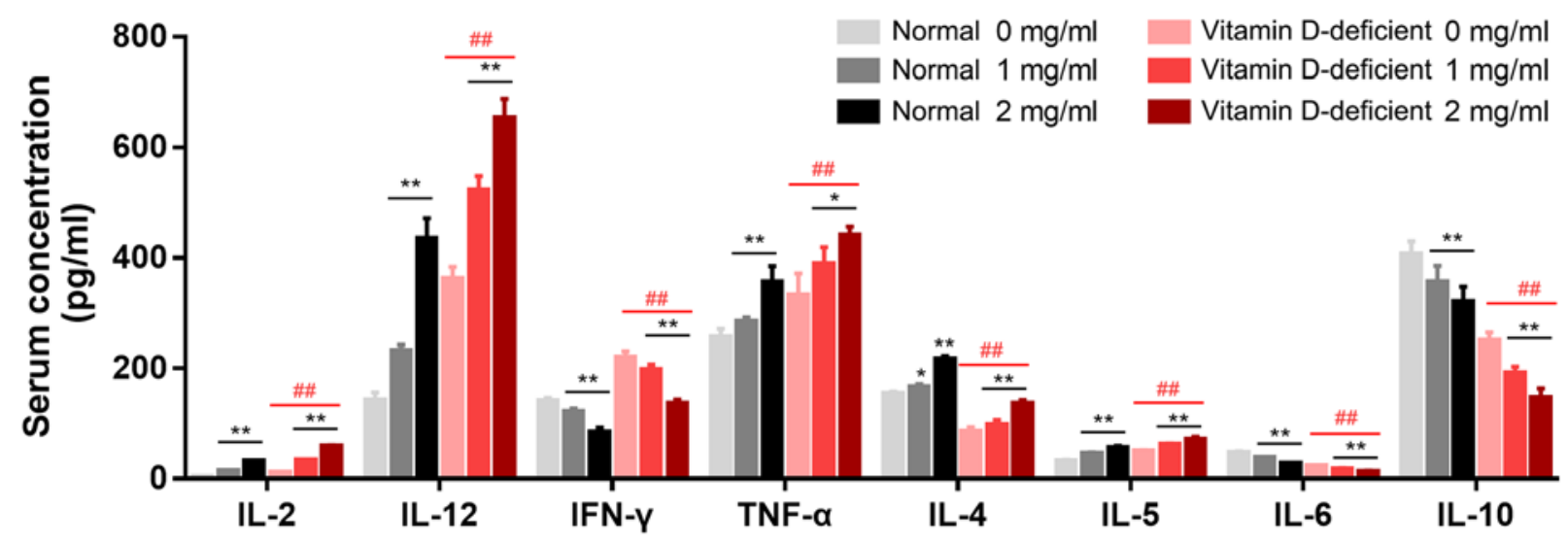

Figure 3. Cytokine levels. The supernatants of the BMDC cultures were collected and the cytokines were detected by ELISA. ${ }^{*}<0.05$ and ${ }^{* *} \mathrm{P}<0.01 \mathrm{vs.} 0 \mathrm{mg} / \mathrm{ml}$ in the normal control or vitamin $\mathrm{D}$-deficiency groups. ${ }^{\# \#} \mathrm{P}<0.01$, vitamin $\mathrm{D}$-deficiency group vs. normal control group. BMDC, bone marrow-derived dendritic cell; IL, interleukin; IFN- $\gamma$, interferon- $\gamma$; TNF- $\alpha$, tumor necrosis factor- $\alpha$.

clusters. On the sixth day of culture, numerous DC clusters were suspended in the medium. There was a large number of needle-like protrusions on the surface of the cell membranes, which is a typical feature of DC morphology (Fig. 2A).

BCG stimulates the maturity of BMDCs. The blood cell count plate revealed that the proportions of DCs in each of the normal groups were as follows: Normal group, $\sim 10 \%$; normal $+1 \mathrm{mg} / \mathrm{ml}$ BCG stimulation group, $\sim 50 \%$; and normal $+2 \mathrm{mg} / \mathrm{ml} \mathrm{BCG}$ stimulation group, $\sim 85 \%$. The DC content in the vitamin D-deficient groups were as follows: Vitamin D-deficient mice model group, $\sim 15 \%$; model $+1 \mathrm{mg} / \mathrm{ml} \mathrm{BCG}$ stimulation group, $\sim 78 \%$; and model $+2 \mathrm{mg} / \mathrm{ml} \mathrm{BCG}$ stimulation group, $\sim 95 \%$ (Fig. 2B).
Phenotypic analysis of the DCs. Flow cytometry was used to examine the expression levels of the surface molecules of DCs. The average positive rates for CD11c, CD80, major histocompatibility complex class I (MHC-1), MHC-II and CD86 were as follows: In the control group $(0 \mathrm{mg} / \mathrm{ml} \mathrm{BCG}), 69.4$, $74.5,76.8,72.2$ and $15.3 \%$, respectively; in the $1 \mathrm{mg} / \mathrm{ml} \mathrm{BCG}$ group, 75.1, 62, 57.9, 71.6 and 12\%, respectively; and in the $2 \mathrm{mg} / \mathrm{ml} \mathrm{BCG}$ group, 82.5, 32.6, 31.6, 66.0 and $8.4 \%$, respectively (Fig. 2C). In the vitamin D-deficient mice model groups, the average positive rates of CD11c, CD80, MHC-1, MHC-II and CD86 were as follows: In the $0 \mathrm{mg} / \mathrm{ml}$ BCG group, 84.9 , $66.0,67.4,48.5$ and $25.0 \%$, respectively; in the $1 \mathrm{mg} / \mathrm{ml} \mathrm{BCG}$ group, $87.3,52.3,47.6,36.2$ and $15.3 \%$, respectively; and in the 
A
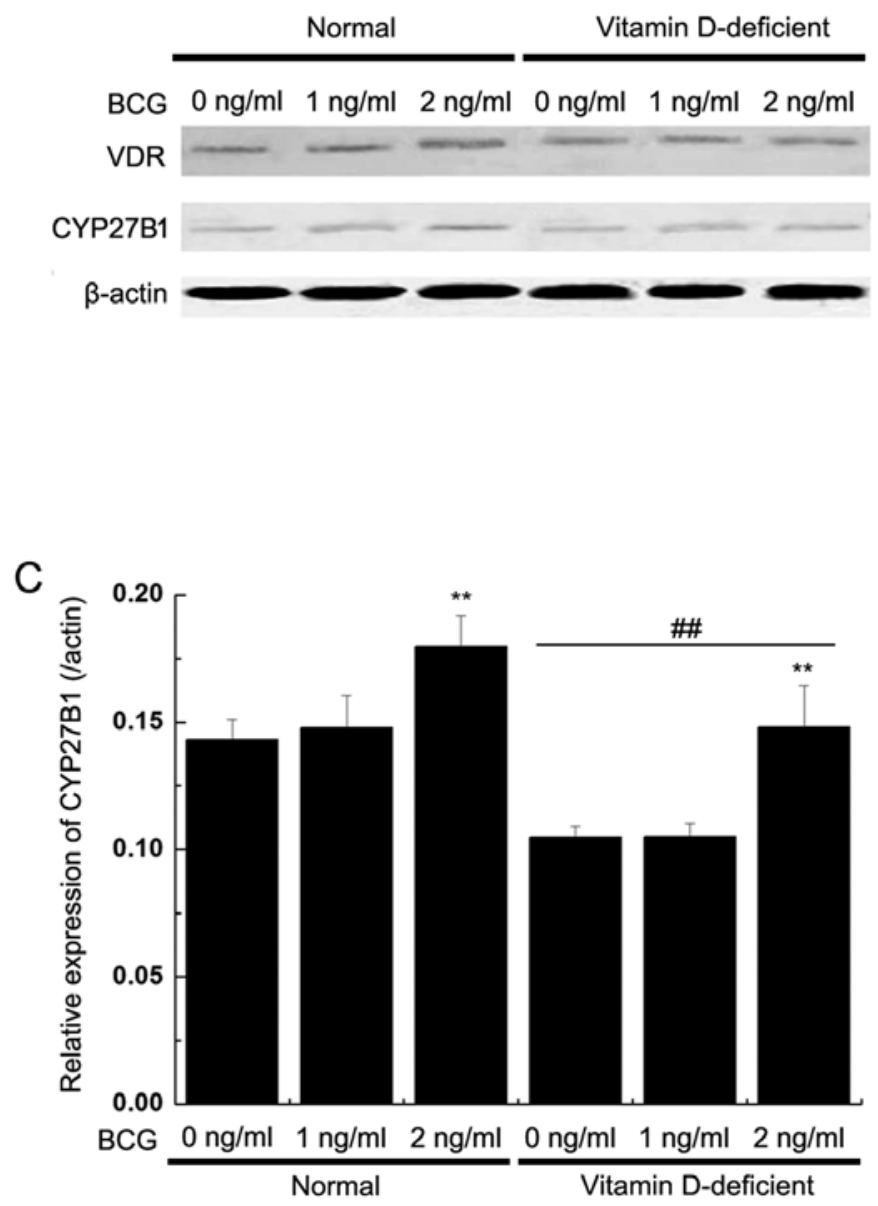

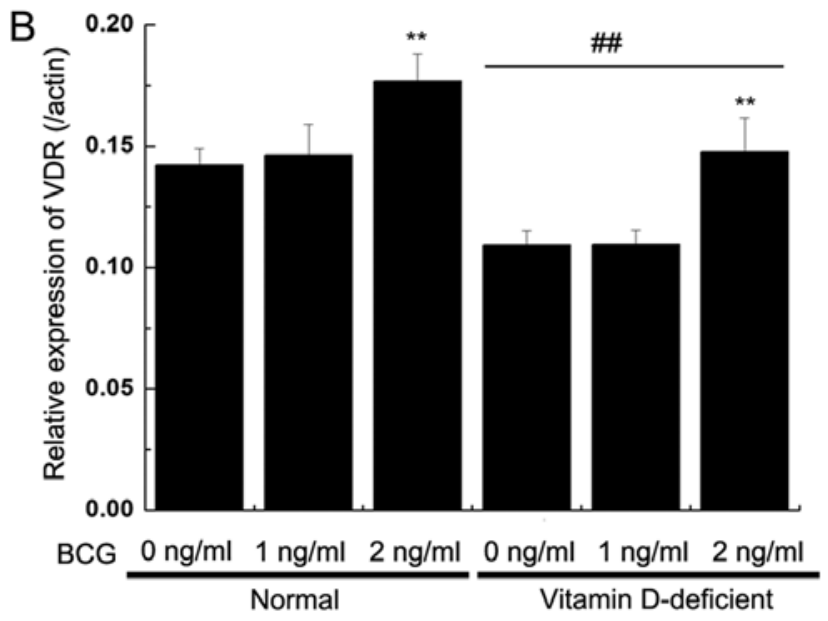

D

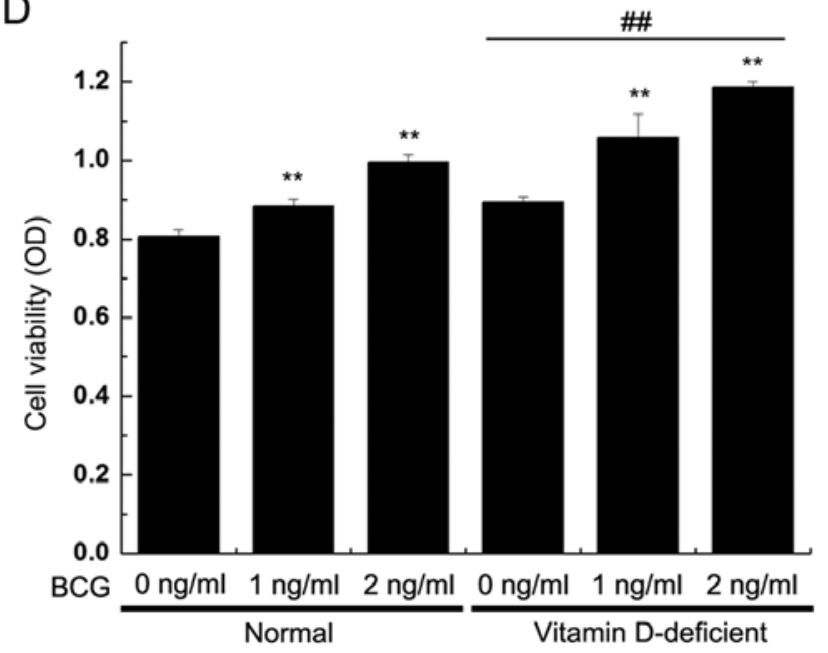

Figure 4. Effects of BCG on DCs and the viability of T lymphocytes cocultured with DCs. (A) The expression of VDR and CYP27B1 in BMDCs following BCG stimulation. (B and C) Quantitative analysis of the expression of (B) VDR and (C) CYP27B1. (D) The viability of the T lymphocytes cocultured with BMDCs and with the administration of BCG. ${ }^{* *} \mathrm{P}<0.01 \mathrm{vs.} 0 \mathrm{mg} / \mathrm{ml}$ in the normal control or vitamin $\mathrm{D}$-deficiency groups. ${ }^{\# \#} \mathrm{P}<0.01$, vitamin $\mathrm{D}$-deficiency group vs. normal control group. BCG, Bacillus Calmette-Guérin; DCs, dendritic cells; BMDC, bone marrow-derived dendritic cell; VDR, vitamin D receptors; CYP27B1, 25-hydroxyvitamin D-1 $\alpha$ hydroxylase, mitochondrial.

$2 \mathrm{mg} / \mathrm{ml}$ BCG group, 89.6, 36.2, 23.1, 23.5 and 5.5\%, respectively (Fig. 2C). The levels of these surface molecules in the vitamin D-deficient mice model group following BCG treatment were significantly different compared with the control groups $(\mathrm{P}<0.01$; Fig. 2D).

Production of cytokines in BMDCs. The levels of IL-2, IL-12, IFN- $\gamma$, TNF- $\alpha$ and IL-5 were significantly increased, and those of IL-4, IL-6 and IL-10 were decreased in the media of the BMDCs from the vitamin D-deficient mice when compared with the normal mice (Fig. 3). In the presence of $1 \mathrm{mg} / \mathrm{ml} \mathrm{BCG}$, the levels of IL-2 $(\mathrm{P}<0.01)$, IL-12 $(\mathrm{P}<0.01)$ and IL-5 $(\mathrm{P}<0.01)$ were significantly increased in the BMDCs from the vitamin $\mathrm{D}$-deficient mice compared with the control mice, while those of IFN- $\gamma(\mathrm{P}<0.05)$ and IL-6 $(\mathrm{P}<0.05)$ were significantly decreased, and those of TNF- $\alpha$, IL-4 and IL-10 were not significantly different. In the presence of BCG, the levels of IL-2, IL-12, IFN- $\gamma$, TNF- $\alpha$ and IL-5 were significantly increased in the BMDCs from the vitamin D-deficient mice in a concentration-dependent manner, while those of IFN- $\gamma(\mathrm{P}<0.01)$ and IL-10 $(\mathrm{P}<0.05)$ were significantly reduced.
The differences among the cytokines in the BMDCs from the normal and vitamin D-deficient mice were significant in the presence of BCG (Fig. 3).

$V D R$ and CYP27B1 protein expression. The western blot analysis results revealed that the expression levels of the VDR and CYP27B1 proteins were decreased in the BMDCs from the vitamin D-deficient mice compared with the normal mice, but BCG $(2 \mathrm{mg} / \mathrm{ml})$ significantly increased the expression levels of VDR and CYP27B1. In the normal mice group, the expression levels of VDR were also significantly increased in the BMDCs following BCG stimulation $(2 \mathrm{mg} / \mathrm{ml})$. The two proteins exhibited similar patterns of expression in each model group (Fig. 4A-C).

Viability of T lymphocytes is induced by DCs. The induced DCs were mixed with allogeneic T lymphocytes on day 6 , with different concentrations of BCG-stimulated maturations for an additional $24 \mathrm{~h}$. The $\mathrm{CD} 4^{+} \mathrm{T}$ cells were mixed with equal amounts of DCs and then incubated for 3 days. Subsequently, the viability of the $\mathrm{CD} 4^{+} \mathrm{T}$ cells was observed. The MTT results 
demonstrated that $\mathrm{T}$ cell viability was markedly increased in the coculture with BMDCs from the vitamin D-deficient mice, compared to those cocultured with BMDCs from the normal mice. T cell viability was additionally increased by BCG treatment (Fig. 4D).

\section{Discussion}

Vitamin D deficiency is more likely to be a risk factor for tuberculosis than a consequence of it $(21,22)$. Studies on the status of vitamin D deficiency with the response of the immune system to tuberculosis infection are urgently required, along with clarification of the mechanisms of vitamin D-based prevention and treatment of tuberculosis.

Penna and Adorini (23) demonstrated that 1,25(OH)2D3 may inhibit the differentiation and maturation of DCs and affect their activity. In the present study, the changes in the phenotypes and cytokines releases of DCs derived from vitamin D-deficient mice were observed under treatment with different concentrations of BCG. Using a BMDC co-culture system, the viability of $\mathrm{T}$ cells was observed under different BCG treatment conditions. The results revealed that the positive rates of CD86 and CD11c in the DCs from vitamin D-deficient mice were increased compared with the normal mice, and the positive rates of MHC-I, MHC II and CD80 were decreased. The expression of the BMDC differentiation-associated surface molecules MHC-I, MHC-II, CD80 and CD86 was significantly inhibited by BCG in a concentration-dependent manner. CD11c is an important marker for the identification of BMDCs. CD11c expression was upregulated by BCG in a concentration-dependent manner. These results suggest that BCG promotes the immune function and specificity of DCs.

$1,25(\mathrm{OH}) 2 \mathrm{D} 3$ regulates the immune system by inhibiting the maturation of DCs, affecting the first stage of the immune response (23). In the present study, the viability of $\mathrm{T}$ cells cocultured with BMDCs from normal mice in the presence of BCG was decreased compared with vitamin D-deficient mice. A previous study demonstrated that $\mathrm{CD}^{+} \mathrm{T}$ cells produce different types of cytokines based on cell clones in mice (24). Th1 cells primarily express IL- 2 and IFN- $\gamma$, enhancing the cytotoxicity of killer cells and stimulating delayed type hypersensitivity. Th2 cells primarily express IL-4, IL-5 and IL-10, promoting the production of antibodies and mediating the immune response. An imbalance of Th1 and Th2 cells induces immune escape of tumor cells and infection with bacteria and viruses, and results in allergic and autoimmune diseases, and transplant rejection (25). Th1 and Th2 abnormalities are also significantly associated with the severity of tuberculosis (26). IL-4 is an important cytokine that promotes Th2 cell viability and is positively associated with tissue fibrosis and necrosis (27). IFN- $\gamma$ and IL-2 are essential anti-inflammatory cytokines in tuberculosis (28). IL-6 has been used as a reference indicator for observing the prognosis of patients with tuberculosis (29). IL-10 is a key cytokine in suppressing the Th1 cellular immune responses (30). IL-12 is an important cytokine of Th1 cells that controls Mtb infection and the survival rate of $\mathrm{BALB} / \mathrm{c}$ mice $(27,31)$. The release of cytokines in the immune response is an important function of DCs. In the present study, the levels of IL-2, IL-12, IFN- $\gamma$ and TNF- $\alpha$ in the DCs from normal mice were decreased compared with those from vitamin D-deficient mice, while the levels of IL-4, IL-6 and IL-10 were increased. Treatment with BCG reversed the levels of those cytokines in a concentration-dependent manner.

In the present study, it was observed that vitamin D may affect cytokine secretion. The expression levels of CPY27B1 and VDR protein in the BMDCs from vitamin D-deficient mice were significantly decreased, and this effect was reversed by BCG stimulation. Vitamin D is a hormone precursor with low biological activity that is only converted into active $1,25(\mathrm{OH}) 2 \mathrm{D} 3$, which may maximize the activation of VDR and exert its important physiological roles in the body (9). The production of active 1,25(OH)2D3 requires 2 important hydroxylation processes: Hydroxylation at position 25 catalyzed by CYP27A1 in the liver mitochondria, and $1 \alpha$ hydroxylation in the kidney catalyzed by CYP27B1 (32). 1,25(OH)2D3 inhibits $\mathrm{DC}$ differentiation and maturation, $\mathrm{B}$ cell differentiation, $\mathrm{T}$ cell proliferation and secretion of IL-12 and TNF- $\alpha(14,33,34)$. $1,25(\mathrm{OH}) 2 \mathrm{D} 3$ may also promote the $\mathrm{Th}-2 \mathrm{~T}$ cell response and production of regulatory $\mathrm{T}$ cells (35). The results of the present study indicated that BCG increased DCs viability and enhanced the immunofunction via CPY27B1 and VDR. Furthermore, BCG increased the viability of $\mathrm{CD} 4^{+} \mathrm{T}$ cells.

In conclusion, BCG increased DCs viability and may enhance immunofunction, which may assist in preventing the risk of tuberculosis in patients with vitamin D deficiency.

\section{Acknowledgements}

Not applicable.

\section{Funding}

The present study was supported by The National Natural Science Foundation of China (grant no. 81301575).

\section{Availability of data and materials}

The datasets analyzed during the present study are available from the corresponding author on reasonable request.

\section{Authors' contributions}

LX and JL designed the experiments. HY, HZ and YL performed the experiments. All authors were involved in the preparation and revision of the manuscript.

\section{Ethics approval and consent to participate}

The present study was approved by the Committee for Experiments with the Use of Laboratory Animals in Shenyang Military Region General Hospital (Shenyang, China; approval no. AE20160823).

\section{Patient consent for publication}

Not applicable.

\section{Competing interests}

The authors declare that they have no competing interests. 


\section{References}

1. Flynn JL: Immunology of tuberculosis and implications in vaccine development. Tuberculosis (Edinb) 84: 93-101, 2004.

2. Liu PT, Stenger S, Li H, Wenzel L, Tan BH, Krutzik SR, Ochoa MT, Schauber J, Wu K, Meinken C, et al: Toll-like receptor triggering of a vitamin D-mediated human antimicrobial response. Science 311: 1770-1773, 2006.

3. Talat N, Perry S, Parsonnet J, Dawood G and Hussain R: Vitamin $\mathrm{D}$ deficiency and tuberculosis progression. Emerg Infect Dis 16 $853-855,2010$

4. Zignol M, van Gemert W, Falzon D, Sismanidis C, Glaziou P, Floyd K and Raviglione M: Surveillance of anti-tuberculosis drug resistance in the world: An updated analysis, 2007-2010. Bull World Health Organ 90: 111-119D, 2012.

5. Goswami R, Mishra SK and Kochupillai N: Prevalence \& potential significance of vitamin D deficiency in Asian Indians. Indian J Med Res 127: 229-238, 2008.

6. Holick MF: Vitamin D deficiency. N Engl J Med 357: 266-281, 2007.

7. Querfeld U: Vitamin D and inflammation. Pediatr Nephrol 28: 605-610, 2013.

8. Dusso AS, Brown AJ and Slatopolsky E: Vitamin D. Am J Physiol Renal Physiol 289: F8-F28, 2005.

9. Pike JW and Meyer MB: The vitamin D receptor: New paradigms for the regulation of gene expression by 1,25-dihydroxyvitamin D3. Rheum Dis Clin North Am 38: 13-27, 2012.

10. Chen Y, Liu W, Sun T, Huang Y, Wang Y, Deb DK, Yoon D, Kong J, Thadhani R and Li YC: 1,25-Dihydroxyvitamin D promotes negative feedback regulation of TLR signaling via targeting microRNA-155-SOCS1 in macrophages. J Immunol 190 3687-3695, 2013

11. Von Essen MR, Kongsbak M, Schjerling P, Olgaard K, Ødum N and Geisler C: Vitamin D controls T cell antigen receptor signaling and activation of human $\mathrm{T}$ cells. Nat Immunol 11 344-349, 2010

12. Rook GA, Steele J, Fraher L, Barker S, Karmali R, O'Riordan J and Stanford J: Vitamin D3, gamma interferon, and control of proliferation of Mycobacterium tuberculosis by human monocytes. Immunology 57: 159-163, 1986.

13. Bikle DD: Vitamin D and the immune system: Role in protection against bacterial infection. Curr Opin Nephrol Hypertens 17: 348-352, 2008.

14. Veldman CM, Cantorna MT and DeLuca HF: Expression of 1,25-dihydroxyvitamin D (3) receptor in the immune system. Arch Biochem Biophys 374: 334-338, 2000.

15. Miziara ID, Magalhaes AT, Santos M, Gomes EF and Oliveira RA Research ethics in animal models. Braz J Otorhinolaryngo (Article in English, Portuguese) 78: 128-131, 2012.

16. Wu SY, Chen WH, Hsieh CL and Lin YW: Abundant expression and functional participation of TRPV1 at Zusanli acupoint (ST36) in mice: Mechanosensitive TRPV1 as an 'acupuncture-responding channel'. BMC Complement Altern Med 14: 96, 2014.

17. Liang Z, Xie Y, Dominguez JA, Breed ER, Yoseph BP, Burd EM, Farris AB, Davidson NO and Coopersmith CM: Intestine-specific deletion of microsomal triglyceride transfer protein increases mortality in aged mice. PLoS One 9: e101828, 2014.

18. https://www.nc3rs.org.uk/arrive-guidelines.

19. Zeng Y and Liu J: Role of glypican-1 in endothelial NOS activation under various steady shear stress magnitudes. Exp Cell Res 348: 184-189, 2016.
20. Zeng Y, Yao X, Liu X, He X, Li L, Liu X, Yan Z, Wu J and Fu BM: Anti-angiogenesis triggers exosomes release from endothelial cells to promote tumor vasculogenesis. J Extracellular Vesicles 8: 1629865, 2019.

21. Gibney KB, MacGregor L, Leder K, Torresi J, Marshall C, Ebeling PR and Biggs BA: Vitamin D deficiency is associated with tuberculosis and latent tuberculosis infection in immigrants from Sub-Saharan Africa. Clin Infect Dis 46: 443-446, 2008.

22. Huang SJ, Wang XH, Liu ZD, Cao WL, Han Y, Ma AG and Xu SF: Vitamin D deficiency and the risk of tuberculosis: A meta-analysis. Drug Des Devel Ther 11: 91-102, 2016.

23. Penna $G$ and Adorini L: 1 Alpha,25-dihydroxyvitamin D3 inhibits differentiation, maturation, activation, and survival of dendritic cells leading to impaired alloreactive $\mathrm{T}$ cell activation. J Immunol 164: 2405-2411, 2000.

24. Mosmann TR, Cherwinski H, Bond MW, Giedlin MA and Coffman RL: Two types of murine helper T cell clone. I. Definition according to profiles of lymphokine activities and secreted proteins. J Immunol 136: 2348-2357, 1986.

25. Lichtner M, Rossi R, Mengoni F, Vignoli S, Colacchia B, Massetti AP, Kamga I, Hosmalin A, Vullo V and Mastroianni CM: Circulating dendritic cells and interferon-alpha production in patients with tuberculosis: Correlation with clinical outcome and treatment response. Clin Exp Immunol 143: 329-337, 2006.

26. Dominguez J, De Souza-Galvao M, Ruiz-Manzano J, Latorre I, Prat C, Lacoma A, Milà C, Jiménez MA, Blanco S, Maldonado J, et al: T-cell responses to the mycobacterium tuberculosis-specific antigens in active tuberculosis patients at the beginning, during, and after antituberculosis treatment. Diagn Microbiol Infect Dis 63: 43-51, 2009.

27. Infante-Duarte $\mathrm{C}$ and Kamradt $\mathrm{T}$ : Th1/Th2 balance in infection. Springer Semin Immunopathol 21: 317-338, 1999.

28. He XY, Xiao L, Chen HB, Hao J, Li J, Wang YJ, He K, Gao Y and Shi BY: T regulatory cells and Th1/Th2 cytokines in peripheral blood from tuberculosis patients. Eur J Clin Microbiol Infect Dis 29: 643-650, 2010.

29. Nemeth J, Winkler HM, Boeck L, Adegnika AA, Clement E, Mve TM, Kremsner PG and Winkler S: Specific cytokine patterns of pulmonary tuberculosis in Central Africa. Clin Immunol 138: $50-59,2011$

30. Handzel ZT, Barak V, Altman Y, Bibi H, Lidgi M, Iancovici-Kidon M, Yassky D and Raz M: Increased Th1 and Th2 type cytokine production in patients with active tuberculosis. Isr Med Assoc J 9: 479-483, 2007.

31. Flynn JL, Goldstein MM, Triebold KJ, Sypek J, Wolf S and Bloom BR: IL-12 increases resistance of BALB/c mice to mycobacterium tuberculosis infection. J Immunol 155: 2515-2524, 1995.

32. Tissandié E, Guéguen Y, Lobaccaro JM, Aigueperse J and Souidi M: Vitamin D: Metabolism, regulation and associated diseases. Med Sci (Paris) 22: 1095-1100, 2006 (In French).

33. Nebbioso M, Buomprisco G, Pascarella A and Pescosolido N: Modulatory effects of 1,25-dihydroxyvitamin D3 on eye disorders: A critical review. Crit Rev Food Sci Nutr 57: 559-565, 2017.

34. Boonstra A, Barrat FJ, Crain C, Heath VL, Savelkoul HF and O'Garra A: 1 $\alpha, 25$-Dihydroxyvitamin D3 has a direct effect on naive $\mathrm{CD} 4^{+} \mathrm{T}$ Cells to enhance the development of $\mathrm{Th} 2$ cells. J Immunol 167: 4974-4980, 2001.

35. Gregori S, Casorati M, Amuchastegui S, Smiroldo S, Davalli AM and Adorini L: Regulatory T cells induced by 1 alpha,25-dihydroxyvitamin D3 and mycophenolate mofetil treatment mediate transplantation tolerance. J Immunol 167: 1945-1953, 2001. 